\title{
Trends in engineering education for additive manufacturing in the industry 4.0 era: a systematic literature review
}

\author{
Barbara Motyl ${ }^{1}$ (D) Stefano Filippi ${ }^{2}$ (B)
}

Received: 10 March 2020 / Accepted: 6 October 2020 / Published online: 21 October 2020

(c) The Author(s) 2020

\begin{abstract}
Additive manufacturing represents one of the most promising and innovative technologies of the moment. In fact, it is considered among the nine technological pillars on which Industry 4.0 is based. In particular, it has received a lot of interest from industries, educational institutions and government agencies. For these reasons, it is necessary to develop and train a specialised workforce and to prepare it for these new opportunities. This work aims to investigate, through the completion of a survey based on a systematic review of the literature, the current state of education and dissemination of educational practices related to the training of young engineers at university on the issues of additive manufacturing and related to Industry 4.0. The results show that the introduction of additive manufacturing education represents an important leverage in the preparation of young engineers who benefit from it both in terms of personal preparation and in terms of learning and refining different skills. However, certain aspects, linked to the need to have adequate equipment and a properly trained teaching staff, should not be overlooked.
\end{abstract}

Keywords Industry $4.0 \cdot$ Additive manufacturing $\cdot 3 \mathrm{D}$ printing $\cdot$ Engineering education $\cdot$ Systematic literature review

\section{Introduction and background}

Additive Manufacturing-AM-is formally defined as the "process of joining materials to make parts from 3D model data, usually layer upon layer" [1]. It represents one of the most promising and innovative technologies at the moment. In fact, it is considered among the nine technological pillars on which Industry 4.0 is based [2]. Previously perceived only as a rapid prototyping technique, AM has now evolved into a real production process for the production of fully functional objects with an increasing diffusion in different industrial sectors [3-5]. In particular, of vital importance, from the point of view of the evolution of the production system, and considering the spread of digitalization practices inherent to Industry 4.0,and the need to train technical

Barbara Motyl

barbara.motyl@uniud.it

Stefano Filippi

stefano.filippi@uniud.it

1 DMIF, University of Udine, Via delle Scienze 206, Udine, Italy

2 DPIA, University of Udine, Via delle Scienze 206, Udine, Italy professionals with new skills and in step with the times, is the proper education in the use of these new technologies [6].

This work wants to investigate, through the completion of a survey based on systematic literature review, the current state of the dissemination of the educational practices related to the training of young engineers in university on AM issues.

The document is organized as follows. After the introductory section, Sect. 2 describes the research method adopted. Then, in Sect. 3 a meta-analysis of the data is reported, while in Sect. 4 the observations on the research questions asked are reported. Finally, conclusions and possible future developments are presented.

\section{Research methodology}

Systematic literature reviews (SLR), represents a widely adopted review method in the medical sector [7]. Now, it has been successfully applied to other scientific fields, in particular to many researches related to Industrial Engineering and management and other technical sectors [4,5]. The overviews of the results of the SLRs have the potential to develop research issues that are not very detailed or completely new, and to draw objective conclusions. Using well-defined search 


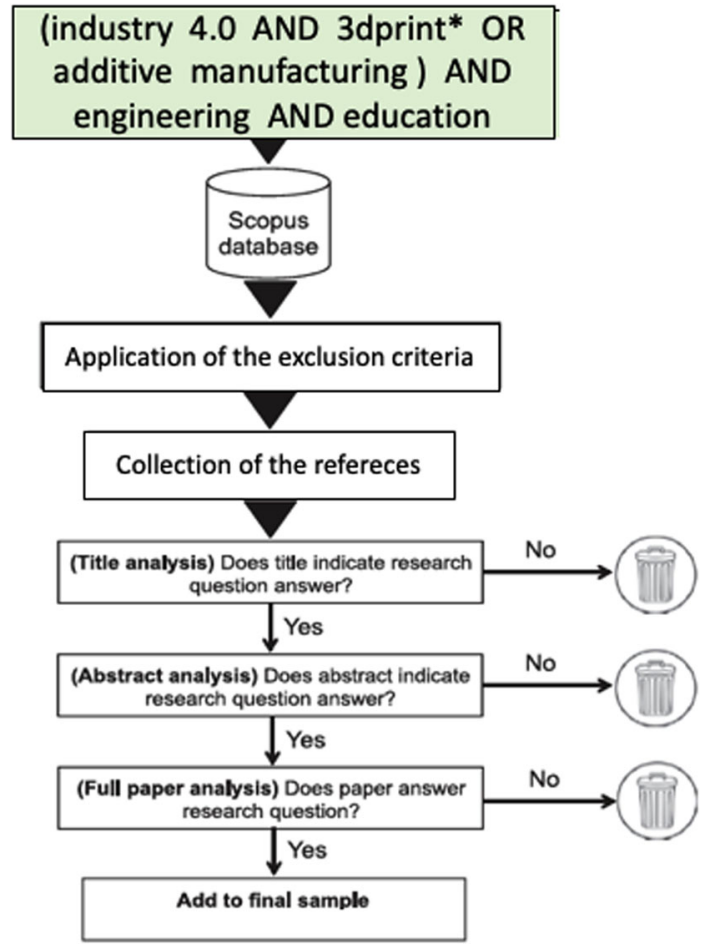

Fig. 1 Flowchart of the SLR used approach

criteria, carefully selecting keywords and setting inclusion or exclusion criteria for the documents to be analysed, reviewers can filter their corresponding search documents to get a final sample of documents that can address their problem under investigation. A well-defined research strategy ensures transparency and replicability, making it less likely that the results of the review are less objective.

For this research, the question posed is defined as follows: RQ1: "What are the educational strategies adopted at university level, in the preparation of young engineers, that involve the use of Additive Manufacturing techniques or 3D printing in general?". The term 3D printing has also been introduced as it is often used as a synonym for AM. Consequently, the search string used is as follows: (industry 4.0 AND 3dprint* OR additive manufacturing) AND engineering AND education. It was left intentionally vague to allow for a wide coverage and it was searched across all fields in published papers. The search was carried out in the Scopus DB. In Fig. 1 is illustrated the flowchart of the SLR approach used. The search protocol matched 256 documents. The following exclusion criteria were applied: documents written not English; document without full text available; documents written before 2012; editorials documents.

After this selection the numbers of matching documents has dropped to 248 . Two other series of filters were carried out: an analysis of the title and an analysis of the abstract, which brought the number of documents to be fully analysed to 30 .

\section{Results of meta-analysis of the documents}

This extended abstract highlights the data related to the metaanalysis of the selected documents. Considering the year of publication, the distribution of the articles analysed is concentrated in 2019 with 17 documents, followed by 2018 with 8 documents, in 2017 and 2020 we have respectively 2 documents and in 2016 only 1 . Considering the type of publications, they are mostly journal papers (15) and conference proceeding or book chapters (15). The geographical distribution of the corresponding authors sees the predominance of the provenance of the studies from the USA with 6 documents, followed by Germany with 5, then Italy, Mexico with 3 documents each. Considering the educational field, these courses are mainly offered for mechanical and materials engineering.

\section{Answer to research question and discussion}

To answer the research question RQ1: "What are the educational strategies adopted at university level, in the preparation of young engineers, that involve the use of additive manufacturing techniques or 3D printing in general?" The following considerations can be made.

From the complete reading of the full texts of the 30 selected documents, what emerges is a strong interest in improving the education of engineering students through the introduction of courses or workshops dedicated to Industry 4.0 subjects, in particular to manufacturing improvement and to the use and deepening of AM techniques for production. In all the documents it is pointed out that also the advent of the fourth industrial revolution implies, as for the previous ones, a transformation of the different work roles, especially technical, and how there is the need to introduce new skills. In particular, this change is required starting from training institutions, schools and universities that will have to prepare the new workers and allow their constant updating also in lifelong learning.

From a more strictly educational point of view, and to better answer the research question, the most representative articles are as follows. In [8-10] reviews on the state of AM education are presented. What emerges is a fundamental importance of this type of teaching for the adequate preparation of young engineers, especially in the mechanical and manufacturing fields [9] In addition, the presence of dedicated courses and entire specialization courses in AM (in countries such as the USA, UK and Spain) starts to be noted [8]. What we can deduce is a great interest in the dissemination of knowledge related to these issues, also dictated by specific company requests or government incentive programs [11]. Another significant point is the belief that AM or 
3DP is a fundamental competence for students of mechanical and industrial engineering as it is related to product design and development and production/manufacturing in general $[9,10]$. Among the main advantages of learning and using AM and 3DP methods and techniques, there are the better understanding and deepening of problems, the improvement of design and visualization skills and the increase in the ability to use computer-aided design applications. In addition, the use of learning by making or Do It Yourself modes involve students more closely by facilitating the understanding of theoretical topics and stimulating independent learning [12-14]. However, there are also some disadvantages represented in particular by the need to have teachers trained on these issues and with a good level of knowledge of the particularities of these techniques $[9,10]$. Another disadvantage is represented by the cost of equipment that is not always irrelevant and/or the realization of laboratories, FabLabs or Learning Factories $[13,15,16]$ Not least, the change in the type of teaching approach, more oriented in this case to active learning and direct participation of students with project-based learning methods is not always well seen by the teaching staff. In conclusion, what emerges, however, is the need for change and revision of the whole programs of engineering courses according to these new needs. In particular, it is perceived that these skills must absolutely enrich the training of engineering students to make them more and more prepared for insertion into the current world of work where skills related to all the enabled technologies of Industry 4.0 are in great demand. In fact, regarding AM, it allows students to learn design and manufacturing through direct interaction with the results of their efforts, improving learning and training and helping to develop their soft skills. Another interesting finding is the considerable interest that can be perceived in this knowledge in all countries in Europe, and especially in emerging countries worldwide.

\section{Conclusions}

In conclusion, the following considerations can be drawn on the SLR investigation method used and the results obtained. The SLR method is very promising as it allows us to highlight the developmental and evolutionary trends of the various research strands investigated. This method lends itself particularly well to highlight underdeveloped themes of investigation and for this reason the practice of using SLRs is becoming increasingly popular also in the field of industrial research. As far as the investigation of educational practices related to AM it is planned to extend the current research to other DBs and to use also the so-called snowball approach starting from the references of the most cited articles. As far as the answer to the research question is concerned, what emerges is a particular ferment and interest for AM in general both as a technical subject and for the working methodology that it involves, especially in recent years, given its strong link with the Industry 4.0 framework.

Funding Open access funding provided by Università degli Studi di Udine within the CRUI-CARE Agreement..

Open Access This article is licensed under a Creative Commons Attribution 4.0 International License, which permits use, sharing, adaptation, distribution and reproduction in any medium or format, as long as you give appropriate credit to the original author(s) and the source, provide a link to the Creative Commons licence, and indicate if changes were made. The images or other third party material in this article are included in the article's Creative Commons licence, unless indicated otherwise in a credit line to the material. If material is not included in the article's Creative Commons licence and your intended use is not permitted by statutory regulation or exceeds the permitted use, you will need to obtain permission directly from the copyright holder. To view a copy of this licence, visit http://creativecomm ons.org/licenses/by/4.0/.

\section{References}

1. ISO ASTM 59900, 2015: Additive Manufacturing-General Principles e Terminology. International Organization for Standardization, Geneva, Switzerland

2. Kagermann, H., Helbig, J., Hellinger, A., Wahlster, W.: Recommendations for Implementing the strategic initiative INDUSTRIE 4.0: securing the future of German manufacturing industry. https://www.din.de/blob/76902/e8cac883f42bf28536e7e816599 $3 \mathrm{f} 1 \mathrm{fd} /$ recommendations-for-implementing-industry-4-0-data.pdf (2013). Accessed 10 March 2020

3. Kellens, K., Baumers, M., Gutowski, T.G., Flanagan, W., Lifset, R., Duflou, J.R.: Environmental dimensions of additive manufacturing: mapping application domains and their environmental implications. J. Ind. Ecol. 21, S49eS68 (2017). https://doi.org/10.1111/ jiec. 12629

4. Saade, M.R.M., Yahia, A., Amor, B.: How has LCA been applied to 3D printing? A systematic literature review and recommendations for future studies. J. Clean. Prod. 244, 118803 (2020). https://doi. org/10.1016/j.jclepro.2019.118803

5. Egger, J., Masood, T.: Augmented reality in support of intelligent manufacturing - a systematic literature review. Comput. Ind. Eng. 140, 106195 (2020). https://doi.org/10.1016/j.cie.2019.106195

6. Motyl, B., Baronio, G., Uberti, S., Speranza, D., Filippi, S.: How will change the future engineers' skills in the Industry 4.0 framework? A questionnaire survey. Procedia Manuf. 11, 1501-1509 (2017). https://doi.org/10.1016/j.promfg.2017.07.282

7. Liberati, A., Altman, D.G., Tetzlaff, J., Mulrow, C., Gøtzsche, P.C., et al.: The PRISMA statement for reporting systematic reviews and meta-analyses of studies that evaluate health care interventions: explanation and elaboration. PLoS Med 6(7), e1000100 (2009). https://doi.org/10.1371/journal.pmed.1000100

8. Mehta, P.U.: A Systematic Review of Additive Manufacturing Education: Toward Engineering Education Research in AM. In: 126th ASEE Annual Conference and Exposition: Charged Up for the Next 125 Years, ASEE 2019; Tampa Convention Center, Tampa; United States; 15-19 June 2019; Code 157034. https:// peer.asee.org/a-systematic-review-of-additive-manufacturingeducation-toward-engineering-education-research-in-am

9. Alabi, M.O., de Beer, D.J., Wichers, H., Kloppers, C.P.: Framework for effective additive manufacturing education: a case study 
of South African universities. Rapid Prototyp J (2019). https://doi. org/10.1108/RPJ-02-2019-0041

10. Chong, S., Pan, G.T., Chin, J., Show, P.L., Yang, T.C.K., Huang, C.M.: Integration of 3D printing and Industry 4.0 into engineering teaching. Sustainability 10(11), 3960 (2018). https://doi.org/10.33 90/su10113960

11. Nepal, B.P., Pagilla, P.R., Srinivasa, A., Moturu, P.K., Bukkapatnam, S.: Board 115: Preparing Next Generation of Manufacturing Leaders: A Case of REU Site in Cybermanufacturing. In: 2019 ASEE Annual Conference \& Exposition. Tampa, Florida. https:// peer.asee.org/32197

12. Keaveney, S.G., Dowling, D.P.: Application of additive manufacturing in design \& manufacturing engineering education. In: 2018 2nd International Symposium on Small-Scale Intelligent Manufacturing Systems (SIMS), pp. 1-6. https://doi.org/10.1109/sims.201 8.8355289

13. Angrisani, L., Arpaia, P., Bonavolontá, F., Moccaldi, N., Moriello, R.S.L.: A "learning small enterprise" networked with a FabLab: an academic course 4.0 in instrumentation and measurement. Measurement 150, 107063 (2020). https://doi.org/10.1016/ j.measurement.2019.107063
14. Barth, H.: Fabrication Laboratory as the Learning Environment for Higher Education. In: Proceedings of the 10th International Multi-Conferences on Complexity, Informatics and Cybernetics, (IMCIC 2019), Orlando, Florida, USA, March 12-15, 2019, vol. 2, pp. 194-196. International Institute of Informatics and Systemics (2019)

15. Hsieh, S.J.: Lessons Learned from Remote Access 3-D Printing Machine for Manufacturing Education. In: 2019 ASEE Annual Conference \& Exposition. Tampa, Florida. https://peer.asee.org/3 3061 (2019)

16. Akundi, A.: Enhancing Additive Manufacturing Education Using Virtual Rapid Prototyping Simulator Tool. In: 2017 ASEE Annual Conference \& Exposition, Columbus, Ohio. https://peer.asee.org/ 28271 (2017)

Publisher's Note Springer Nature remains neutral with regard to jurisdictional claims in published maps and institutional affiliations. 